\section{A rare complication of endoloop-assisted polyp- ectomy: adhesion of snare and endoloop}

Endoloop-assisted polypectomy may minimize the risk of bleeding after endoscopic resection of large pedunculated colorectal adenomas [ $1-3]$. To the best of our knowledge, this is the first report of a rare complication of this technique caused by adhesion of the snare and endoloop.

A 67-year-old man was referred to our endoscopy unit for polypectomy of colorectal adenomas detected during a colonoscopy carried out at a private office. Colonoscopy was performed at our department and 11 adenomas in the colorectum, ranging in diameter between $5 \mathrm{~mm}$ and $25 \mathrm{~mm}$, were removed by snare polypectomy without complications. Finally, it was decided to remove the largest adenoma, a pedunculated adenoma with a diameter of $30 \mathrm{~mm}$ located in the descending colon ( Fig. 1 a), using endoloop-assisted polypectomy.

After indigo carmine had been injected into the stalk of the polyp ( $\bullet$ Fig. $1 \mathbf{b}$ ), the stalk was ligated close to its base by an endoloop ( Fig.1c). As the snare was closed around the stalk (about $5 \mathrm{~mm}$ distal to the endoloop), it went unnoticed that part of the plastic tail belonging to the endoloop had also been caught by the snare. As a result, application of electric current during the polypectomy not only cut off the adenoma but also caused the plastic tail of the endoloop to melt, resulting in adhesion of the snare and endoloop $(\checkmark$ Fig.1d). Consequently, the snare was stuck to the endoloop and could not be removed via the working channel of the endoscope.

To avoid complications that might be caused by abruptly pulling the snare, a second endoscope (gastroscope) was inserted into the descending colon and a forceps inserted through the gastroscope was used to grasp and stabilize the tail of the endoloop ( $\bullet$ Fig. 1 e). It was then possible to release the stuck snare by gently pulling it away from the stabilizing forceps ( $\bullet$ Fig.1f). Histologic examination revealed a tubulovillous adenoma with high grade dysplasia.
We conclude that adhesion of a snare and endoloop is a rare complication of endoloop-assisted polypectomy. A safe distance must be kept between the endoloop and the snare when performing this procedure and caution is required when closing the snare to avoid the endoloop getting caught. Should it occur, the complication can be managed by introducing a second endoscope.

\section{Endoscopy_UCTN_Code_CPL_1AJ_2AC}

\section{Competing interests: None}

\section{Alexander Tischer, Theresia Schober, Margret Karner, Stephan Moser, Michael Schleicher, Michael Gschwantler}

Wilhelminenspital, Department of Internal Medicine IV, Vienna, Austria

\section{References}

$1 \mathrm{Ji}$ JS, Lee SW, Kim TH et al. Comparison of prophylactic clip and endoloop application for the prevention of postpolypectomy bleeding in pedunculated colonic polyps: a prospective, randomized, multicenter study. Endoscopy 2014; 46: 598-604

2 Kouklakis G, Mpoumponaris A, Gatopoulou A et al. Endoscopic resection of large pedunculated colonic polyps and risk of post-
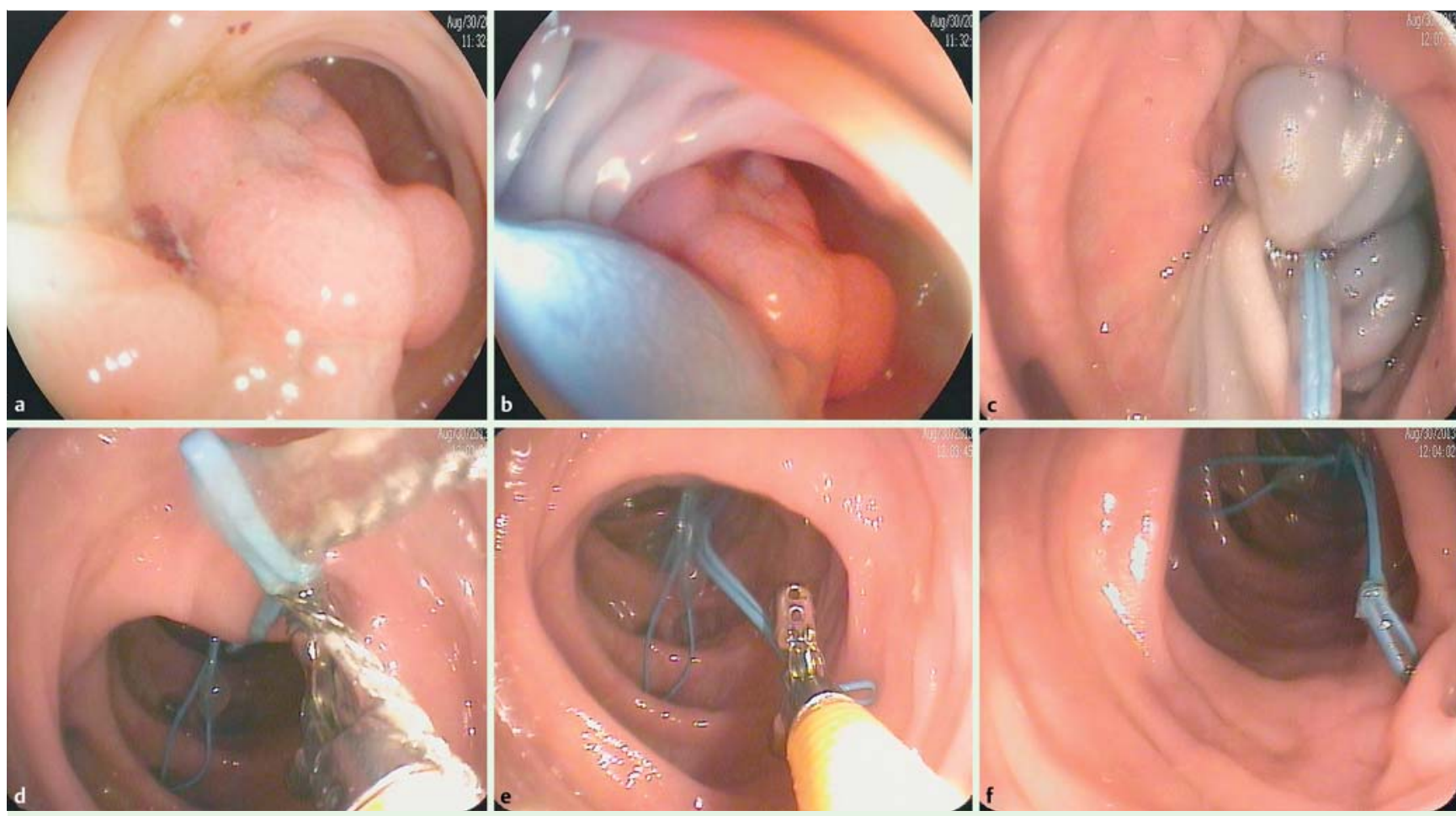

Fig. 1 Endoscopic views showing: $\mathbf{a}$ a pedunculated adenoma with a diameter of $30 \mathrm{~mm}$ in the descending colon; $\mathbf{b}$ the stalk of the polyp after an injection of indigo carmine; $\mathbf{c l i g a t i o n}$ of the stalk of the polyp by an endoloop; $\mathbf{d}$ adhesion of the snare and endoloop; $\mathbf{e}$ a forceps inserted into the colon through a second endoscope being used to grasp and stabilize the tail of the endoloop; $\mathbf{f}$ the stuck snare being released. 
polypectomy bleeding with adrenaline injection versus endoloop and hemoclip: a prospective, randomized study. Surg Endosc 2009; 23: 2732-2737

3 Katsinelos P, Kountouras J, Paroutoglou G et al. Endoloop-assisted polypectomy for large pedunculated colorectal polyps. Surg Endosc 2006; 20: 1257-1261

\section{Bibliography}

Dol http://dx.doi.org/

10.1055/s-0042-104278

Endoscopy 2016; 48: E117-E118

(C) Georg Thieme Verlag KG

Stuttgart · New York

ISSN 0013-726X

\section{Corresponding author}

\section{Michael Gschwantler, MD}

Wilhelminenspital, Department of Internal Medicine IV

Montleartstrasse 37

A-1160 Vienna

Austria

Fax: +43-1-491502409

michael.gschwantler@wienkav.at 